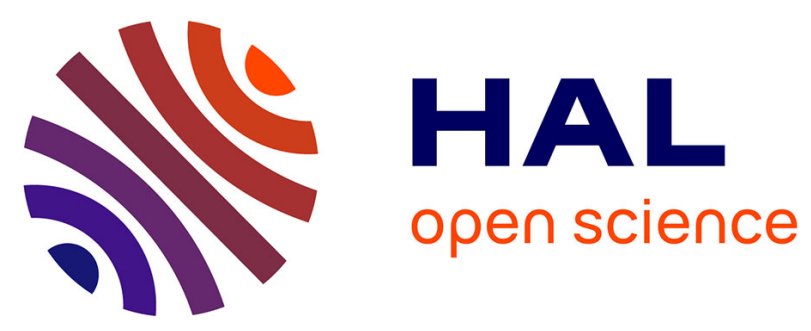

\title{
A monocomponent bifunctional benzophenone-carbazole type II photoinitiator for LED photoinitiating systems
}

Shaohui Liu, Damien Brunel, Ke Sun, Yangyang Xu, Fabrice Morlet-Savary, Bernadette Graff, Pu Xiao, Frédéric Dumur, Jacques Lalevee

\section{- To cite this version:}

Shaohui Liu, Damien Brunel, Ke Sun, Yangyang Xu, Fabrice Morlet-Savary, et al.. A monocomponent bifunctional benzophenone-carbazole type II photoinitiator for LED photoinitiating systems. Polymer Chemistry, 2020, 11 (21), pp.3551-3556. 10.1039/D0PY00644K . hal-02868803

\section{HAL Id: hal-02868803 https://hal.science/hal-02868803}

Submitted on $20 \mathrm{Jul} 2020$

HAL is a multi-disciplinary open access archive for the deposit and dissemination of scientific research documents, whether they are published or not. The documents may come from teaching and research institutions in France or abroad, or from public or private research centers.
L'archive ouverte pluridisciplinaire HAL, est destinée au dépôt et à la diffusion de documents scientifiques de niveau recherche, publiés ou non, émanant des établissements d'enseignement et de recherche français ou étrangers, des laboratoires publics ou privés. 


\section{A monocomponent bifunctional benzophenone-carbazole type II}

\section{photoinitiator for LED photoinitiating systems}

Shaohui Liu ${ }^{1}$, Damien Brunel ${ }^{2}$, Ke Sun ${ }^{1}$, Yangyang Xu${ }^{1}$, Fabrice Morlet-Savary ${ }^{1}$, Bernadette Graff $^{1}, \mathrm{Pu} \mathrm{Xiao}^{3 *}$, Frédéric Dumur $^{2 *}$, Jacques Lalevée ${ }^{1 *}$

${ }^{1}$ Institut de Science des Matériaux de Mulhouse, IS2M-UMR CNRS 7361, UHA, 15, rue Jean Starcky, Cedex 68057 Mulhouse, France.

${ }^{2}$ Aix Marseille Univ, CNRS, ICR UMR 7273, F-13397 Marseille, France

${ }^{3}$ Research School of Chemistry, Australian National University, Canberra, ACT 2601, Australia.

*Corresponding authors: pu.xiao@anu.edu.au; Frederic.dumur@univ-amu.fr; jacques.lalevee@uha.fr

Abstract: A bifunctional benzophenone-carbazole-based photoinitiator BPC was designed from its molecular structure viewpoint. To get this, two benzoyl substituents were introduced as peripheral groups of carbazole so that a molecule in which two benzophenones were fused to one carbazole unit could be obtained in a one-step procedure. As a result of this combination, synergetic effects are thus attended. Interestingly, BPC could efficiently initiate the free radical photopolymerization (FRP) of acrylates without addition of any extra hydrogen donors demonstrating a monocomponent Type II behavior but also fast photoinitiation rates were obtained in the presence of an amine and/or an iodonium salt with a LED@365 nm. Meanwhile, $\mathrm{BPC}$ can also interact with the iodonium salt to generate cationic species for the cationic photopolymerization $(\mathrm{CP})$ of epoxides. $\mathrm{BPC}$ was found as a versatile photoinitiator that can be used for both radical and cationic polymerizations. The best photoinitiating system (PIS) determined during the FRP tests was selected for 3D printing experiments. Steady state photolysis and fluorescence quenching experiments were carried out to verify the interaction between BPC and the different additives in the excited state. Electron spin resonance-spin trapping experiments successfully distinguished the free radicals generated by the different PISs and the proposed electron transfer mechanisms 
are also discussed.

Keywords: Photoinitiator, Carbazole, Benzophenone, 3D printing.

The development of photopolymerization systems is constantly evolving due to their numerous attractive features. This polymerization technique benefits from several advantages compared to the traditional solution-phase polymerization such as no emission of volatile organic compounds (VOCs), low energy consumption, low operating temperature and low cost irradiation setups ${ }^{1-2}$. Light is also a traceless reagent that can be abundantly used in chemical transformations without risking having residues within the polymer network. Photopolymerization is a technique which transforms liquid monomers into solid polymers under light irradiation. Compared to thermal polymerization, photopolymerization has a unique space and time controllability. Because of this advantage, photopolymerization could be used in many special fields (e.g. dental restoration and microelectronic processing) ${ }^{3-5}$. Traditional UV light sources (e.g. Hg lamp) release high heat, generate ozone during polymerization processes and also have expensive cost (expensive light sources). These obvious drawbacks have adversely affected both the development of new photoinitiating systems but also the scope of applicability of photopolymerization. Gradually, lightemitting diodes (LEDs) as irradiation sources have attracted more and more attention because of their low cost, less heat release and good security ${ }^{6-8}$. However, many of the commercial photoinitiators (PIs) can be only used with the traditional UV light sources, these molecules having limited absorption in the near UV/visible range. For example, benzophenone (BP) is a cheap and widely used Type II PI when used with amines as co-initiators. However, BP hardly absorbs for $\lambda>340 \mathrm{~nm}$ and can't be used for near UV LED@365, 385 or $395 \mathrm{~nm}$ that are now characterized by a widespread use in polymer applications and industry. Therefore, it is significant to explore new high performance photoinitiating systems (PISs) better matching the emission spectra of LEDs $^{9-12}$. In recent years, many works focused on the development of dye photosensitized systems which have long absorption wavelengths and high efficiency 
under LEDs irradiation ${ }^{13}$. Dyes acting as PI or photosensitizer (PS) absorb light and interact with co-initiators in the excited states through electron transfer to generate active species ${ }^{14-16}$. Naphthalimide, pyrene, anthracene, carbazole, etc, are all used in free radical photopolymerization (FRP) and cationic photopolymerization $(\mathrm{CP})^{13}$. To improve the photochemical reactivity or to obtain additional properties, dyes are usually decorated with various substituents by mean of chemical engineering. Owing to its outstanding electron-donating ability and its good optical properties, carbazole is frequently used to design functional PIs. Carbazole group bearing with nitro, aldehyde, bromine, ferrocene groups notably exhibited good performances for photopolymerization carried out under visible light ${ }^{17-18}$. Carbazole can also be easily modified by chemical engineering, its solubility can be easily tuned by functionalization of the NH group with alkyl chains so that this building block has been at the basis of numerous PIs. Extension of aromaticity can also be easily obtained by ring-fusing or by introducing a peripheral $\pi$-conjugated system, enabling to red-shift its absorption towards the visible range ${ }^{17,19-21}$.

In this work, two benzoyl groups were introduced onto the carbazole core to produce a novel PI (9-Ethyl-9H-carbazole-3,6-diyl)bis(phenylmethanone) (BPC). Unlike other substituents, the benzoyl group and the aromatic ring of carbazole compose a benzophenone which is a famous Type II PI. What's more, BPC is composed of a structure combining two benzophenone groups and a carbazole (scheme 1). As a result of this hybrid structure, a good or even improved photoinitiation ability are thus expected from this novel PI for wavelengths that are currently not accessible for neat BP. The chemical structures of BPC and other compounds used in this work are shown in Scheme 1. BPC has been reported previously but only as photosensitizer for iodonium and sulfonium salts in cationic polymerization ${ }^{22-23}$. To the best of our knowledge, BPC was never reported as radical PI.

Trimethylolpropane triacrylate (TMPTA) and (3,4-epoxycyclohexane)methyl 3,4-epoxycyclohexylcarboxylate (EPOX) are used as benchmark monomers for free radical polymerization FRP and cationic polymerization CP, respectively. Bis(4-tertbutylphenyl)iodonium hexafluorophosphate (Iod), ethyl 4-(dimethylamino)benzoate 
(EDB) and triethanolamine (TEOA) are added into PISs to promote the photopolymerization and to study the photochemical properties. The photoinitiation ability of BPC was evaluated and the photoinitiation mechanism was also investigated. In addition, the application of the best PIS to 3D printing was carried out.

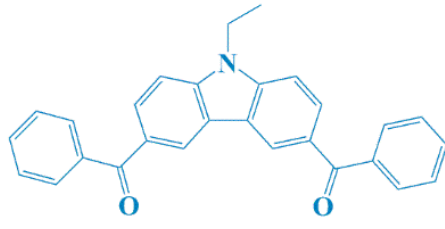

BPC

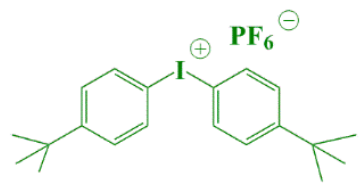

Iod

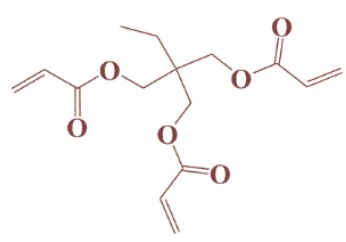

TMPTA

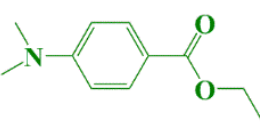

EDB

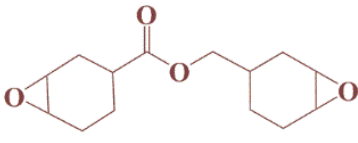

EPOX

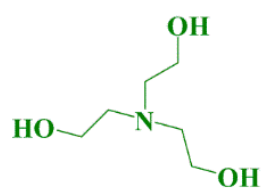

TEOA

Scheme 1. The structures of BPC and other compounds used in this study.

(9-Ethyl-9H-carbazole-3,6-diyl)bis(phenylmethanone) BPC was synthesized in one step using a Friedel-Craft reaction opposing 9-Ethyl-9H-carbazole to benzoyl chloride in the presence of aluminium chloride. The targeted compound could be isolated as a solid in $82 \%$ yield (see the characterization in supporting information).

The UV-Vis absorption spectrum of BPC in acetonitrile is shown in Figure 1A. The maximum absorption wavelength $\lambda_{\max }$ is $342 \mathrm{~nm}$ and the molar extinction coefficient at the maximum absorption wavelength $\varepsilon_{\max }$ is $18600 \mathrm{M}^{-1} \mathrm{~cm}^{-1}$. Molecular orbital calculations on the optimized geometries are depicted in Figure 1B. A $\pi-\pi^{*}$ charge transfer transition is observed between the highest occupied molecular orbital (HOMO) and the lowest unoccupied molecular orbital (LUMO) mainly located on the carbazole and the difunctional benzophenone moieties, respectively. The strong conjugation extension also contributes to redshift the absorption maximum at longer absorption wavelength compared to the unsubstituted carbazole or benzophenone which ensures a good overlap of the absorption of BPC and the emission spectra of near 
UV LEDs (e.g. LED@365 nm used in this work).

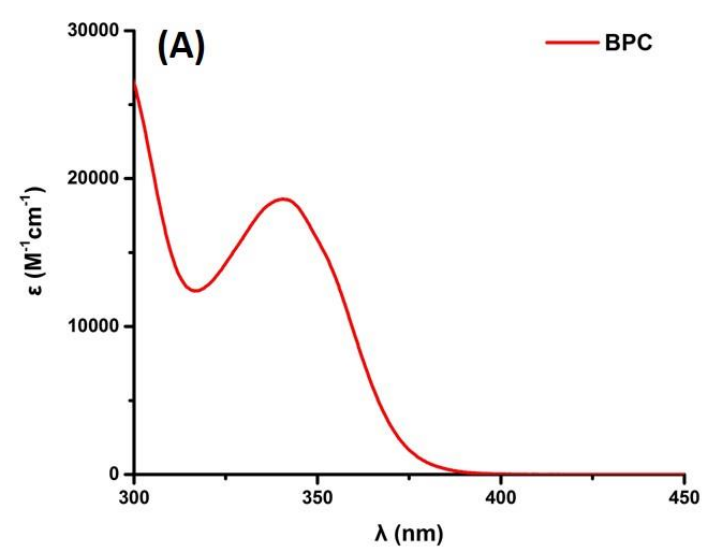

(B)

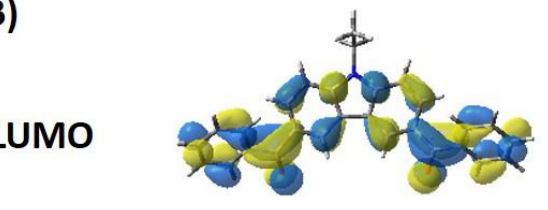

LUMO

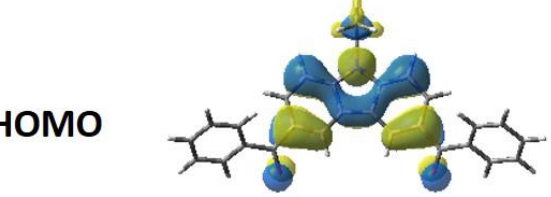

Figure 1. (A) UV-Vis absorption spectrum of BPC, (B) Contour plots of the HOMO and the LUMO energy levels of BPC (B3LYP/6-31G* level).

The polymerization profiles of TMPTA for FRP and EPOX for CP are depicted in Figure 2 and the final reactive function conversions are summarized in Table 1. Remarkably, BPC alone could effectively initiate the polymerization of TMPTA upon LED@365 nm irradiation and a final acrylate function conversion as high as 65\% could be determined by Real-Time Fourier Transformed Infrared Spectroscopy (RT-FTIR) measurements. For BP alone, no polymerization occurs in these conditions. Interestingly, BPC has a one-component Type II PI behavior. When EDB acting potentially as a $\mathrm{H}$ donor (co-initiator) was used in combination with $\mathrm{BPC}$, the polymerization rate was greatly boosted. It indicates that the difunctional benzophenone keep a high capacity for hydrogen abstraction in BPC structure. Consequently, the bimolecular interaction between BPC and EDB contributes to the FRP, as observed in traditional Type II systems ${ }^{24}$. Remarkably, the final acrylate function conversion of BPC/EDB system is slightly higher than the well-established Isopropyl-9H-thioxanthen-9-one (ITX)/EDB system for the same molar fraction (Figure S1) demonstrating its excellent initiating behavior in Type II systems (similar polymerization rates were found for BPC and ITX). The polymerization of TMPTA in the presence of BP and EDB leads to very poor polymerization profiles compared to 
BPC/EDB (Figure 2A; curve 2 vs. curve 6) upon LED@365 nm irradiation also showing the clear superiority of BPC to BP.

In addition, the two-component $\mathrm{BPC} / \mathrm{Iod}$ and the three-component $\mathrm{BPC} / \mathrm{EDB} / \mathrm{Iod}$ PISs exhibited excellent efficiencies. Iod acts as a familiar electron acceptor which promotes the polymerization well ${ }^{24}$. Especially, the BPC/EDB/Iod three-component system showed the best efficiencies from both the final function conversion and the polymerization rate viewpoint (see the chemical mechanisms in Scheme 2).

The CP of EPOX in the presence of BPC/Iod $(0.5 \% / 1 \% \mathrm{w} / \mathrm{w})$ was carried out under air. The final epoxy function conversion of is $46 \%$. It demonstrates that BPC is also appropriate to $\mathrm{CP}$ demonstrating a versatile behavior.
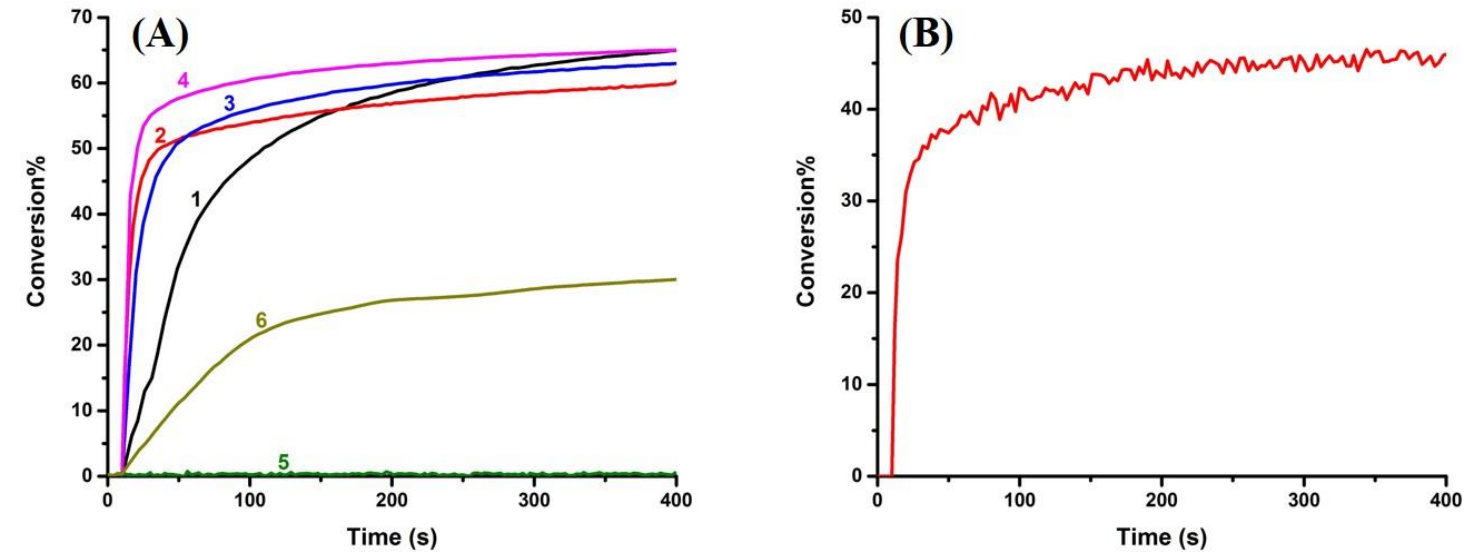

Figure 2. (A) Photopolymerization profiles of TMPTA (acrylate function conversion vs. time) in laminate upon LED@365 nm irradiation in the presence of (1) BPC alone $(1.5 \%$, w), (2) BPC/EDB $(0.5 \% / 1 \%, w / w)$, (3) $\mathrm{BPC} / \operatorname{Iod}(0.5 \% / 1 \%, \mathrm{w} / \mathrm{w})$, (4) BPC/EDB/Iod (0.5\%/1\%/1\%, w/w/w), (5) BP alone (1.5\%, w), (6) BP/EDB (0.5\%/1\%, $\mathrm{w} / \mathrm{w})$; (B) Photopolymerization profile of EPOX (epoxy function conversion vs. time) upon LED@365 nm irradiation under air in the presence of BPC/Iod $(0.5 \% / 1 \% \mathrm{w} / \mathrm{w})$. The irradiation starts for $\mathrm{t}=10 \mathrm{~s}$.

Table 1. Final acrylate function conversions for TMPTA and epoxy function conversion for EPOX upon LED@365 nm irradiation at t=400 s.

\begin{tabular}{|c|c|c|c|c|c|c|c|}
\hline \multirow{2}{*}{ PISs } & \multicolumn{5}{|c|}{ TMPTA } & EPOX \\
\cline { 2 - 8 } & BPC & BPC/EDB & BPC/Iod & BPC/EDB/Iod & BP & BP/EDB & BPC/Iod \\
\hline Conversion \% & 65 & 60 & 63 & 65 & 0 & 30 & 46 \\
\hline
\end{tabular}

Steady state photolysis experiments were carried out to investigate the 
interactions between BPC and additives. The absorption peak of BPC only slightly overlaps with that of EDB so that triethanolamine (TEOA) was used instead of EDB. The UV-Vis absorption spectra of BPC alone (Figure S2A) remained unchanged even after 30 minutes of irradiation and it could be ascribed to the very low concentration of $\mathrm{BPC}$ in acetonitrile preventing its bimolecular interaction. Conversely, photolysis of the BPC/TEOA system (Figure S2B) resulted in a decrease of the absorbance upon irradiation. The consumption of BPC was accompanied with the classical hydrogen abstraction and an electron transfer between the benzophenone moiety in BPC and the amino group in TEOA. A stronger photolysis was observed for a BPC/Iod (Figure S2C) system with formation of photoproduct at $\lambda>375 \mathrm{~nm}$ indicating a strong interaction between BPC and Iod. It is similar with BPC/TEOA/Iod system (Figure S2D) and the isobestic points in photolysis suggest that the interaction in BPC/TEOA/Iod does not generate side-products.

Fluorescence quenching experiments are indicative of the interaction exciting between BPC and the different additives in the excited singlet state. The fluorescence quenching experiments of the BPC/EDB system (Figure S3A) revealed the fluorescence intensity of BPC to decline gradually with the increasing amounts of EDB. The slight deviation of fluorescence emission peaks could be attributed to the charge transfer complex ${ }^{25}$. The fluorescence quenching is also observed for the two-component BPC/Iod system (Figure S3C). High electron transfer quantum yields $\left(\Phi^{\mathrm{et}}\right)$ are calculated (see Table 2) and the fluorescence quenching results indicate the presence of an effective electron transfer between BPC and EDB as well as Iod in the excited singlet state (see Scheme 2).

To investigate the photoinitiation mechanism further, electron spin resonancespin trapping (ESR-ST) experiments were carried out in different PISs with phenyl- $N$ tert-butylnitrone $(\mathrm{PBN})$ as the radical trapping agent. For the irradiation of $\mathrm{BPC}$ alone in solution (Figure S4A), a PBN radical adduct is characterized by hyperfine coupling constants $\mathrm{a}_{\mathrm{N}}=14.2 \mathrm{G}$ and $\mathrm{a}_{\mathrm{H}}=2.6 \mathrm{G}$ that can be assigned to an aminoalkyl radical $\mathrm{BPC}_{(-}$ H) in agreement with ref $^{26}$. Another radical adduct was observed but it can't be fully identified. Therefore, under irradiation, bimolecular hydrogen abstraction can occur 
between a benzophenone moiety and the amino group in carbazole to generate $\mathrm{BPC}_{(-}$ ${ }_{\mathrm{H})}{ }^{\cdot}$ radical which can initiate the FRP effectively. The mechanism is depicted in the following reactions ( $\mathrm{r} 1$ and $\mathrm{r} 2$; Scheme 2$)$. Using the redox potentials of $\mathrm{BPC}\left(\mathrm{E}_{\mathrm{ox}}=\right.$ $1.4 \mathrm{~V}^{23}, \mathrm{E}_{\text {red }}=-1.85 \mathrm{~V} ; \mathrm{E}_{\text {red }}$ is evaluated through $\mathrm{E}_{\text {red }}=\mathrm{E}_{\mathrm{ox}}-\mathrm{E}_{\text {band gap }}{ }^{27}$ and the $\mathrm{E}_{\text {band gap }}$ is obtained by BPC UV-vis spectrum) and the excited singlet state energy $\left(\mathrm{E}_{\mathrm{S} 1}=3.17 \mathrm{eV}\right.$; evaluated here from the crossing point between absorption and fluorescence spectra), the free energy change $(\Delta \mathrm{G})$ for the electron transfer reaction in $\mathrm{r} 2$ is found close to $0.08 \mathrm{eV}$ suggesting a rather favorable process (using $\Delta \mathrm{G}=\mathrm{E}_{\mathrm{ox}}-\mathrm{E}_{\mathrm{red}}-\mathrm{E}_{\mathrm{s} 1}{ }^{28}$ ) (Table 2). Therefore, an electron-followed by proton transfer reaction can be assumed in r2.

$$
\begin{aligned}
& \mathrm{BPC} \rightarrow{ }^{1,3} \mathrm{BPC}(\mathrm{h} v) \\
& { }^{1,3} \mathrm{BPC}+{ }^{1,3} \mathrm{BPC} \rightarrow \mathrm{BPC}^{\cdot-}+\mathrm{BPC}^{\cdot+} \rightarrow \mathrm{BPC}_{-} \mathrm{H}^{\cdot}+\mathrm{BPC}_{(-\mathrm{H})} \cdot
\end{aligned}
$$

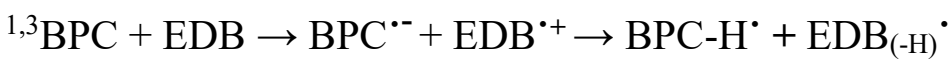

$$
\begin{aligned}
& { }^{1,3} \mathrm{BPC}+\mathrm{Ar}_{2} \mathrm{I}^{+} \rightarrow \mathrm{BPC}^{\cdot+}+\mathrm{Ar}_{2} \mathrm{I}^{\cdot} \rightarrow \mathrm{BPC}^{\cdot+}+\mathrm{Ar}^{\cdot}+\mathrm{ArI} \\
& \mathrm{BPC}-\mathrm{H}^{\cdot}+\mathrm{Ar}_{2} \mathrm{I}^{+} \rightarrow \mathrm{BPC}+\mathrm{Ar}+\mathrm{ArI}+\mathrm{H}^{+} \\
& \mathrm{BPC}^{\cdot+}+\mathrm{EDB} \rightarrow \mathrm{BPC}+\mathrm{EDB}^{\cdot+}
\end{aligned}
$$

Scheme 2. Proposed chemical mechanisms.

Table 2. Electron transfer quantum yields $\left(\Phi^{\mathrm{et}}\right)^{\mathrm{a}}$ and free energy change $(\Delta \mathrm{G})^{\mathrm{b}}$ between BPC excited state and different additives.

\begin{tabular}{|c|c|c|c|c|c|}
\hline & $\Phi^{\mathrm{et}}$ EDB & $\Phi^{\mathrm{et}}$ Iod & $\begin{array}{c}\Delta \mathrm{G}_{(* \mathrm{BPC} / \mathrm{BPC})} \\
/ \mathrm{eV}\end{array}$ & $\begin{array}{c}\Delta \mathrm{G}_{\left({ }^{* B P C} / \mathrm{EDB}\right)} \\
/ \mathrm{eV}^{\mathrm{c}}\end{array}$ & $\begin{array}{c}\Delta \mathrm{G}_{\left({ }^{*} \mathrm{BPC} / \text { Iod }\right)} \\
/ \mathrm{eV}^{\mathrm{d}}\end{array}$ \\
\hline From ${ }^{1} \mathrm{BPC}$ & 0.99 & 0.78 & +0.08 & -0.32 & -1.07 \\
\hline From ${ }^{3} \mathrm{BPC}$ & & & +0.26 & -0.14 & -0.89 \\
\hline
\end{tabular}

\footnotetext{
a: $\Phi^{\mathrm{et}}=\mathrm{K}_{\mathrm{sv}}[$ additive $] /\left(1+\mathrm{K}_{\mathrm{sv}}[\right.$ additive $\left.]\right), \mathrm{K}_{\mathrm{sv}}$ is obtained from Stern-Volmer treatment for fluorescence quenching (Figure S2).

b: $\Delta \mathrm{G}=\mathrm{E}_{\mathrm{ox}}-\mathrm{E}_{\text {red }}-\mathrm{E}^{* 28}, \mathrm{E}^{*}=\mathrm{E}_{\mathrm{S} 1}$ for reaction from ${ }^{1} \mathrm{BPC}=3.17 \mathrm{eV}$ and $\mathrm{E}^{*}=\mathrm{E}_{\mathrm{T} 1}$ for reaction from ${ }^{3} \mathrm{BPC}=2.99$ $\mathrm{eV}^{23}$.

c: an oxidation potential of $1.0 \mathrm{~V}$ was used for $\mathrm{EDB}^{24}$.

$\mathrm{d}$ : a reduction potential of $-0.7 \mathrm{~V}$ was used for $\operatorname{Iod}^{29}$.
} 
The ESR-ST spectrum obtained for the irradiation of the BPC/EDB system is shown in Figure 3A and a radical adduct is characterized by the hyperfine coupling constants $\mathrm{a}_{\mathrm{N}}=14.4 \mathrm{G}$ and $\mathrm{a}_{\mathrm{H}}=2.5 \mathrm{G}$ which are in agreement with $\mathrm{EDB}_{(-\mathrm{H})}$ radical. $^{30}$ Using the free energy change equation, a favorable $\Delta \mathrm{G}$ is found for the ${ }^{1} \mathrm{BPC} / \mathrm{EDB}$ interaction in agreement with a strong BPC/EDB interaction $(\Delta \mathrm{G}=-0.32 \mathrm{eV}$; using an oxidation potential of $1.0 \mathrm{~V}$ for EDB) (Table 2). Therefore, EDB acts as an electron donor and as a $\mathrm{H}$ donor able to generate active species for FRP (r3; Scheme 2) in agreement with better polymerization profiles for BPC/EDB vs. BPC alone.

As shown in the Figure 3B, the irradiation of BPC/Iod solution leads to the formation of a radical adduct characterized by $\mathrm{a}_{\mathrm{N}}=14.3 \mathrm{G}$ and $\mathrm{a}_{\mathrm{H}}=2.1 \mathrm{G}$; typical for the $\mathrm{Ar}{ }^{\cdot}$ radical..$^{31}$ Iod can act as an electron acceptor through the interaction with BPC and lead to aryl radical $\mathrm{Ar}^{\circ}$ and cation $\mathrm{BPC}^{\cdot+}$ which are considered as the initiating species for the FRP and CP respectively ( $\mathrm{r} 4$; Scheme 2). This is in full agreement with the negative free energy change observed for the ${ }^{1} \mathrm{BPC} / \mathrm{Iod}$ interaction (Table 2).

The triplet state pathway for $\mathrm{r} 3$ and $\mathrm{r} 4$ can't be ruled out as favorable $\Delta \mathrm{Gs}$ are calculated (Table 2).

Ar radical also be discovered in $\mathrm{BPC} / \mathrm{EDB} / \mathrm{Iod}$ system as the hyperfine coupling constants $a_{N}=14.3 \mathrm{G}$ and $a_{H}=2.1 \mathrm{G}$ (Figure S4B). Probably, there is a photoredox catalytic cycle in BPC/Iod/EDB system. The electron transfers from BPC- $\mathrm{H}^{\cdot}$ to $\mathrm{Ar}_{2} \mathrm{I}^{+}$ and from $\mathrm{EDB}$ to $\mathrm{BPC}^{\cdot+}$ can regenerate $\mathrm{BPC}$ once again ( $\mathrm{r} 5 \mathrm{a}$ and $\mathrm{r} 5 \mathrm{~b}$; Scheme 2). The slower consumption of BPC during the photolysis of the BPC1/Iod/TEOA system compared to that observed in the BPC1/Iod system also proves the photoredox catalytic cycle. 

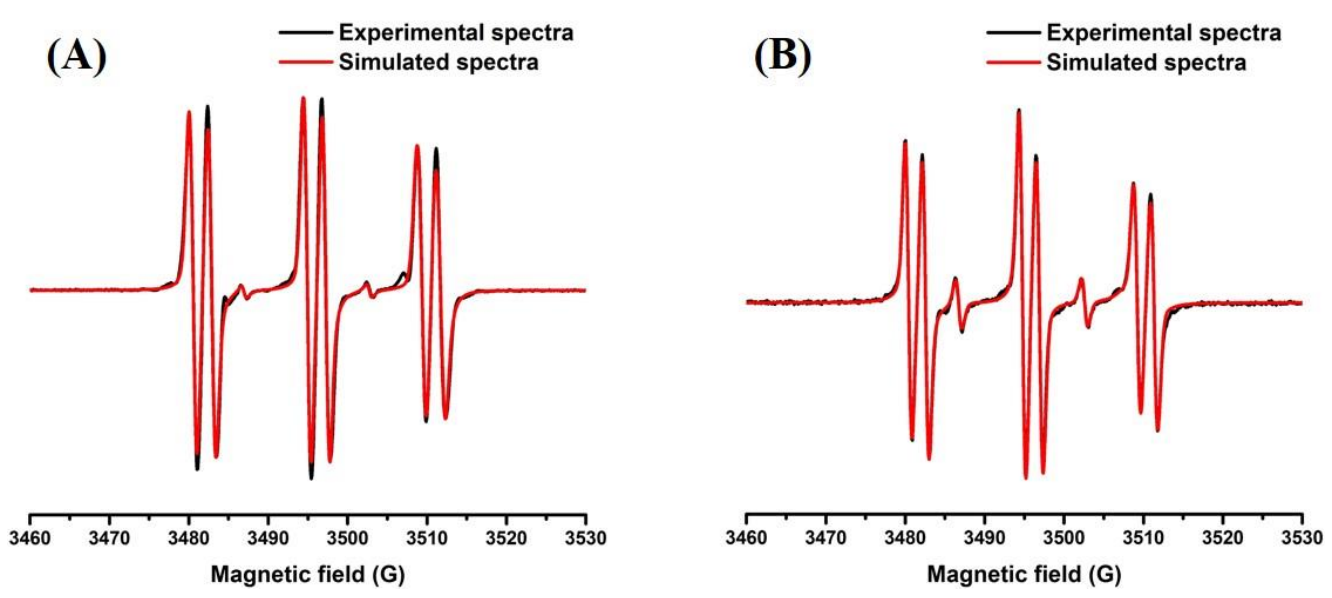

Figure 3. ESR-ST spectra of the radical adducts obtained in the presence of (A) BPC/EDB and (B) BPC/Iod upon LED@375 nm irradiation in tert-butylbenzene.

The BPC/EDB/Iod system with the best performance for the FRP of TMPTA was used in the $3 \mathrm{D}$ printing experiments. The $3 \mathrm{D}$ pattern "BPC" was easily obtained through laser write experiments using a computer-controlled laser diode at $405 \mathrm{~nm}$ and the photopolymerization profile of TMPTA upon $405 \mathrm{~nm}$ irradiation is given in Figure S5. Profiles of the obtained 3D patterns were observed by numerical optical microscopy. As shown in Figure 4, there is an efficient photopolymerization and very good spatial resolution of the 3D patterns (within the size of the laser beam $\sim 50 \mu \mathrm{m}$ ).

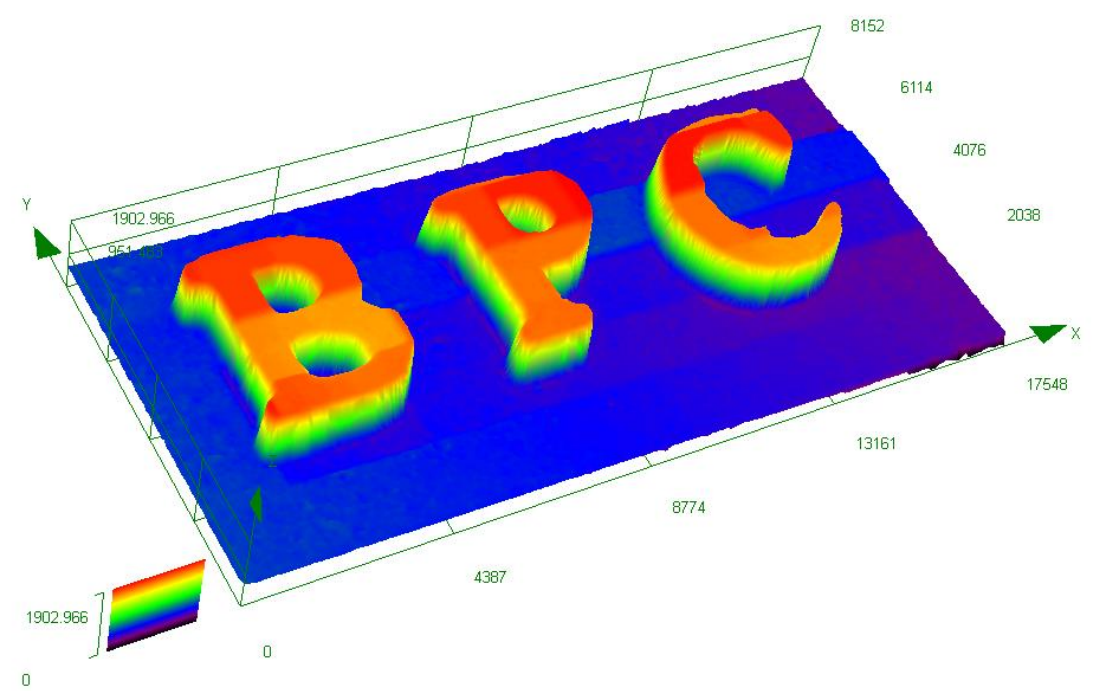

Figure 4. The 3D pattern "BPC" characterized by numerical optical microscopy.

In summary, BPC exhibits good absorption properties and excellent 
photoinitiation ability (@365 or 405 nm). The benzophenone-carbazole coupling structure forms a one-component Type II PI and high reactive function conversion is obtained in the presence of BPC alone in FRP. In combination with EDB and Iod, the polymerization rate could be greatly improved. The photoinitiation mechanism is discussed in detail and the application of BPC/EDB/Iod system on 3D printing is proved effectively. Thanks to its higher molecular weight than BP and difunctional behavior (possibility to be linked to the polymer network by different moieties), BPC is also characterized by low migration properties. The development of other photoinitiators based on the carbazole scaffold is currently under progress.

\section{Experimental Section}

The UV-Vis absorption properties of the different PISs were studied using a JASCO V730 spectrophotometer. The weight percent of BPC, EDB and Iod was calculated from the monomer content. The conversion of the epoxy groups was continuously monitored by Real-Time Fourier Transformed Infrared Spectroscopy (RT-FTIR, JASCO FTIR 4100) at $\sim 790 \mathrm{~cm}^{-1}$ for EPOX and at $\sim 1630 \mathrm{~cm}^{-1}$ for the acrylate functions in TMPTA. The irradiation starts at $\mathrm{t}=10 \mathrm{~s}$. The fluorescence properties of the compounds were studied using the JASCO FP-6200 spectrometer. The ESR-ST experiments were carried out using an X-band spectrometer (Bruker EMX-Plus). Phenyl-N-tert-butylnitrone (PBN) was used as free radical trapping agent. $\mathrm{N}_{2}$ saturated tert-Butylbenzene solutions were irradiated upon LED@375 nm in room temperature. The obtained 3D pattern was analyzed by a numerical optical microscope (OLYMPUS DSX-HRSU).

\section{Acknowledgements}

This project is supported by China Scholarship Council (CSC No. 201906880009). 


\section{References}

1. Yagci, Y.; Jockusch, S.; Turro, N. J., Photoinitiated Polymerization: Advances, Challenges, and Opportunities. Macromolecules 2010, 43 (15), 6245-6260.

2. Sautrot-Ba, P.; Malval, J.-P.; Weiss-Maurin, M.; Paul, J.; Blacha-Grzechnik, A.; Tomane, S.; Mazeran, P.-E.; Lalevée, J.; Langlois, V.; Versace, D.-L., Paprika, Gallic Acid, and Visible Light: The Green Combination for the Synthesis of Biocide Coatings. ACS Sustainable Chemistry \& Engineering 2018, 6 (1), 104-109.

3. Moszner, N.; Fischer, U. K.; Ganster, B.; Liska, R.; Rheinberger, V., Benzoyl germanium derivatives as novel visible light photoinitiators for dental materials. Dental Materials 2008, 24 (7), 901-907.

4. Nguyen, A. K.; Narayan, R. J., Two-photon polymerization for biological applications. Materials Today 2017, 20 (6), 314-322.

5. O'Brien, A. K.; Bowman, C. N., Modeling Thermal and Optical Effects on Photopolymerization Systems. Macromolecules 2003, 36 (20), 7777-7782.

6. Pan, X.; Tasdelen, M. A.; Laun, J.; Junkers, T.; Yagci, Y.; Matyjaszewski, K., Photomediated controlled radical polymerization. Progress in Polymer Science 2016, 62, 73-125.

7. Kutahya, C.; Aykac, F. S.; Yilmaz, G.; Yagci, Y., LED and visible light-induced metal free ATRP using reducible dyes in the presence of amines. Polymer Chemistry 2016, 7 (39), 6094-6098.

8. Xu, Y.-Y.; Ding, Z.-F.; Liu, F.-Y.; Sun, K.; Dietlin, C.; Lalevée, J.; Xiao, P., 3D Printing of Polydiacetylene Photocomposite Materials: Two Wavelengths for Two Orthogonal Chemistries. ACS Applied Materials \& Interfaces 2020, 12 (1), 1658-1664.

9. Dumur, F.; Gigmes, D.; Fouassier, J.-P.; Lalevée, J., Organic Electronics: An El Dorado in the Quest of New Photocatalysts for Polymerization Reactions. Accounts of Chemical Research 2016, 49 (9), 1980 1989.

10. Zhang, J.; Frigoli, M.; Dumur, F.; Xiao, P.; Ronchi, L.; Graff, B.; Morlet-Savary, F.; Fouassier, J. P.; Gigmes, D.; Lalevée, J., Design of Novel Photoinitiators for Radical and Cationic Photopolymerizations under Near UV and Visible LEDs (385, 395, and 405 nm). Macromolecules 2014, 47 (9), 2811-2819.

11. Sari, E.; Mitterbauer, M.; Liska, R.; Yagci, Y., Visible light induced free radical promoted cationic polymerization using acylsilanes. Progress in Organic Coatings 2019, 132, 139-143.

12. Kocaarslan, A.; Kütahya, C.; Keil, D.; Yagci, Y.; Strehmel, B., Near-IR and UV-LED Sensitized Photopolymerization with Onium Salts Comprising Anions of Different Nucleophilicities. ChemPhotoChem 2019, 3 (11), 1127-1132.

13. Xiao, P.; Zhang, J.; Dumur, F.; Tehfe, M. A.; Morlet-Savary, F.; Graff, B.; Gigmes, D.; Fouassier, J. P.; Lalevée, J., Visible light sensitive photoinitiating systems: Recent progress in cationic and radical photopolymerization reactions under soft conditions. Progress in Polymer Science 2015, 41, 32-66.

14. Garra, P.; Dietlin, C.; Morlet-Savary, F.; Dumur, F.; Gigmes, D.; Fouassier, J.-P.; Lalevée, J., Redox twocomponent initiated free radical and cationic polymerizations: Concepts, reactions and applications. Progress in Polymer Science 2019, 94, 33-56.

15. Dadashi-Silab, S.; Doran, S.; Yagci, Y., Photoinduced Electron Transfer Reactions for Macromolecular Syntheses. Chemical Reviews 2016, 116 (17), 10212-10275.

16. Sun, K.; Xu, Y.; Dumur, F.; Morlet-Savary, F.; Chen, H.; Dietlin, C.; Graff, B.; Lalevée, J.; Xiao, P., In silico rational design by molecular modeling of new ketones as photoinitiators in three-component photoinitiating systems: application in 3D printing. Polymer Chemistry 2020, 11 (12), 2230-2242.

17. Al Mousawi, A.; Dumur, F.; Garra, P.; Toufaily, J.; Hamieh, T.; Graff, B.; Gigmes, D.; Fouassier, J. P.; Lalevée, J., Carbazole Scaffold Based Photoinitiator/Photoredox Catalysts: Toward New High 
Performance Photoinitiating Systems and Application in LED Projector 3D Printing Resins. Macromolecules 2017, 50 (7), 2747-2758.

18. Dumur, F., Recent advances on carbazole-based photoinitiators of polymerization. European Polymer Journal 2020, 125, 109503.

19. Al Mousawi, A.; Dumur, F.; Garra, P.; Toufaily, J.; Hamieh, T.; Goubard, F.; Bui, T.-T.; Graff, B.; Gigmes, D.; Pierre Fouassier, J.; Lalevée, J., Azahelicenes as visible light photoinitiators for cationic and radical polymerization: Preparation of photoluminescent polymers and use in high performance LED projector 3D printing resins. Journal of Polymer Science Part A: Polymer Chemistry 2017, 55 (7), 1189-1199.

20. Abdallah, M.; Magaldi, D.; Hijazi, A.; Graff, B.; Dumur, F.; Fouassier, J.-P.; Bui, T.-T.; Goubard, F.; Lalevée, J., Development of new high-performance visible light photoinitiators based on carbazole scaffold and their applications in 3d printing and photocomposite synthesis. Journal of Polymer Science Part A: Polymer Chemistry 2019, 57 (20), 2081-2092.

21. Al Mousawi, A.; Arar, A.; Ibrahim-Ouali, M.; Duval, S.; Dumur, F.; Garra, P.; Toufaily, J.; Hamieh, T.; Graff, B.; Gigmes, D.; Fouassier, J.-P.; Lalevée, J., Carbazole-based compounds as photoinitiators for free radical and cationic polymerization upon near visible light illumination. Photochemical \& Photobiological Sciences 2018, 17 (5), 578-585.

22. Yamamura, T.; Tanabe, T.; Ukachi, T., Photosensitization of Carbazole Derivatives and Application to Photofabrication in Cationic System. Journal of Photopolymer Science and Technology 2000, 13 (1), 117-118.

23. Chen, Y.; Yamamura, T.; Igarashi, K., Photosensitization of carbazole derivatives in cationic polymerization with a novel sensitivity to near-UV light. Journal of Polymer Science Part A: Polymer Chemistry 2000, 38 (1), 90-100.

24. Fouassier, J. P.; Lalevée, J., Photoinitiators for Polymer Synthesis 2012, Wiley, Weinheim.

25. Kim, D.; Scranton, A. B.; Stansbury, J. W., Analysis of association constant for ground-state dyeelectron acceptor complex of photoinitiator systems and the association constant effect on the kinetics of visible-light-induced polymerizations. Journal of Polymer Science Part A: Polymer Chemistry 2009, 47 (5), 1429-1439.

26. Tehfe, M.-A.; Dumur, F.; Graff, B.; Morlet-Savary, F.; Gigmes, D.; Fouassier, J.-P.; Lalevée, J., Pushpull (thio)barbituric acid derivatives in dye photosensitized radical and cationic polymerization reactions under 457/473 nm laser beams or blue LEDs. Polymer Chemistry 2013, 4 (13), 3866-3875.

27. Wu, B.; Liu, X.; Shi, X.; Han, W.; Wang, C.; Jiang, L., Highly photoluminescent and temperaturesensitive $\mathrm{P}, \mathrm{N}, \mathrm{B}$-co-doped carbon quantum dots and their highly sensitive recognition for curcumin. RSC Advances 2019, 9 (15), 8340-8349.

28. Rehm, D.; Weller, A., Kinetics of Fluorescence Quenching by Electron and H-Atom Transfer. Israel Journal of Chemistry 1970, 8 (2), 259-271.

29. Romańczyk, P. P.; Kurek, S. S., The Reduction Potential of Diphenyliodonium Polymerisation Photoinitiator Is Not -0.2V vs. SCE. A Computational Study. Electrochimica Acta 2017, 255, 482-485.

30. Zhang, J.; Zivic, N.; Dumur, F.; Xiao, P.; Graff, B.; Gigmes, D.; Fouassier, J. P.; Lalevée, J., A benzophenone-naphthalimide derivative as versatile photoinitiator of polymerization under near UV and visible lights. Journal of Polymer Science Part A: Polymer Chemistry 2015, 53 (3), 445-451.

31. Al Mousawi, A.; Lara, D. M.; Noirbent, G.; Dumur, F.; Toufaily, J.; Hamieh, T.; Bui, T.-T.; Goubard, F.; Graff, B.; Gigmes, D.; Fouassier, J. P.; Lalevée, J., Carbazole Derivatives with Thermally Activated Delayed Fluorescence Property as Photoinitiators/Photoredox Catalysts for LED 3D Printing Technology. Macromolecules 2017, 50 (13), 4913-4926. 


\section{Supporting Information}

\section{A Bifunctional Benzophenone-Carbazole Photoinitiator for}

\section{LED Photoinitiating Systems}

Shaohui Liu ${ }^{1}$, Damien Brunel ${ }^{2}, K_{e}$ Sun $^{1}$, Yangyang Xu ${ }^{1}$, Fabrice Morlet-Savary ${ }^{1}$, Bernadette Graff $^{1}, \mathrm{Pu} \mathrm{Xiao}^{3 *}$, Frédéric Dumur ${ }^{2 *}$, Jacques Lalevée ${ }^{1 *}$

${ }^{1}$ Institut de Science des Matériaux de Mulhouse, IS2M-UMR CNRS 7361, UHA, 15, rue Jean Starcky, Cedex 68057 Mulhouse, France.

${ }^{2}$ Aix Marseille Univ, CNRS, ICR UMR 7273, F-13397 Marseille, France

${ }^{3}$ Research School of Chemistry, Australian National University, Canberra, ACT 2601, Australia.

*Corresponding authors: pu.xiao@anu.edu.au; Frederic.dumur@univ-amu.fr; jacques.lalevee@uha.fr

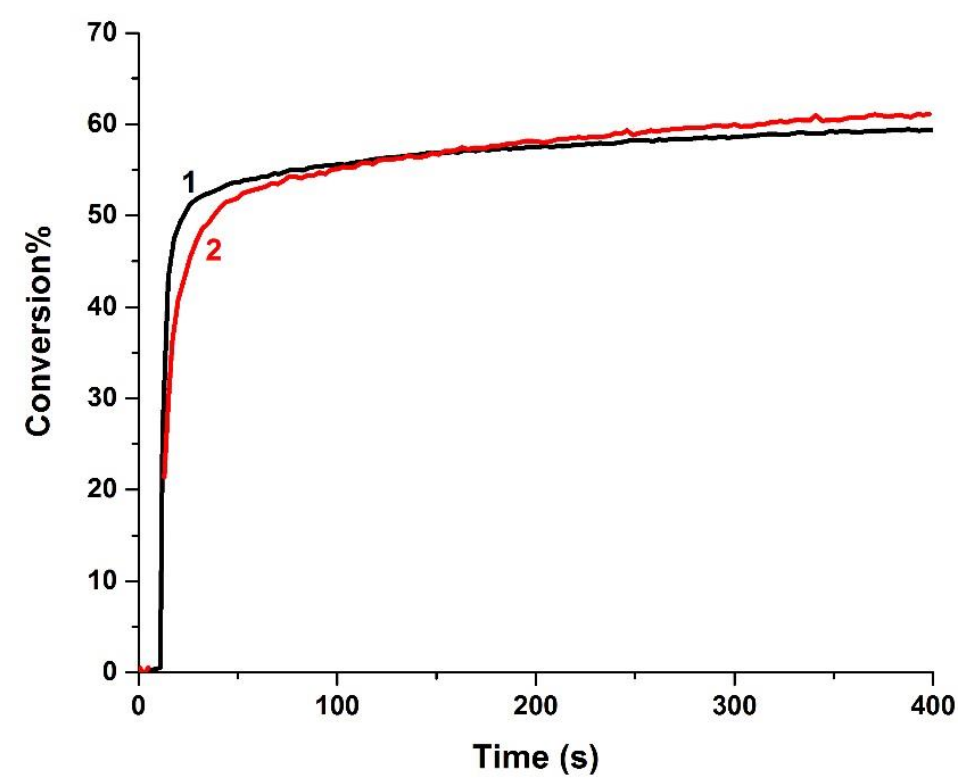

Figure S1. Photopolymerization profiles of TMPTA (acrylate function conversion vs. time) in laminate upon LED@365 nm irradiation in the presence of (1) ITX/EDB $(0.3 \% / 1 \%, \mathrm{~mol} / \mathrm{mol}),(2) \mathrm{BPC} / \mathrm{EDB}(0.3 \% / 1 \%, \mathrm{~mol} / \mathrm{mol})$. The irradiation starts for $\mathrm{t}=$ $10 \mathrm{~s}$. 

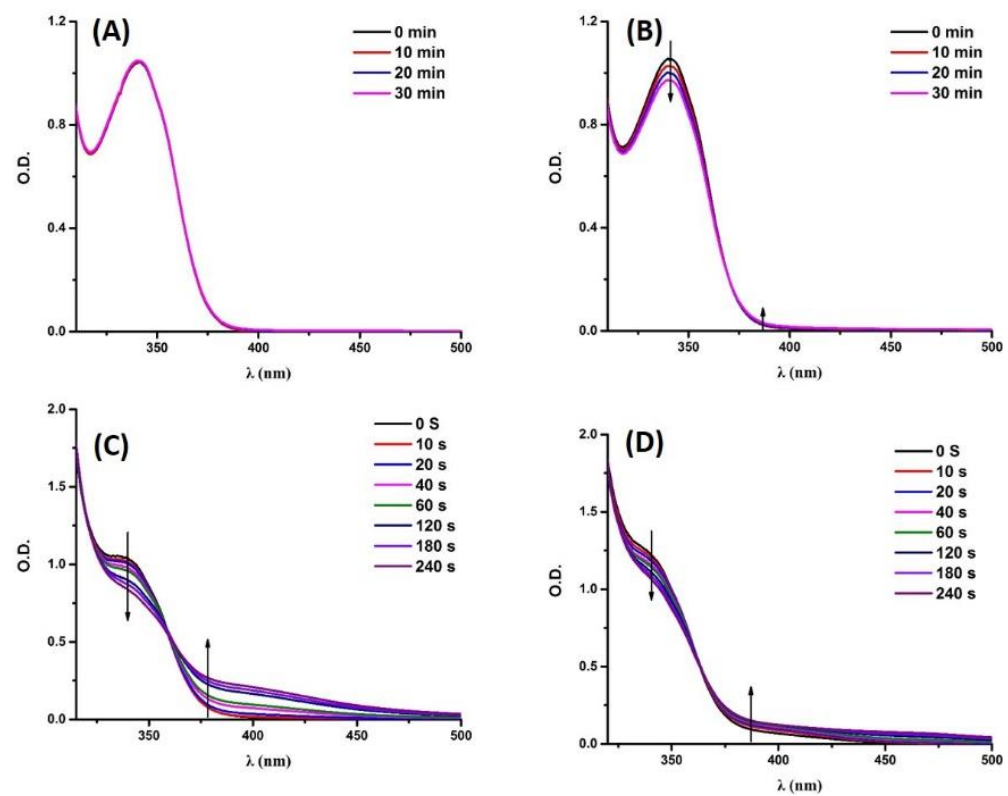

Figure S2. Photolysis of (A) BPC alone, (B) BPC/TEOA, (C) BPC/Iod, (D) BPC/Iod/TEOA upon LED@375 nm irradiation in acetonitrile ([Iod] $=0.01 \mathrm{M}$, $[\mathrm{TEOA}]=0.01 \mathrm{M})$.
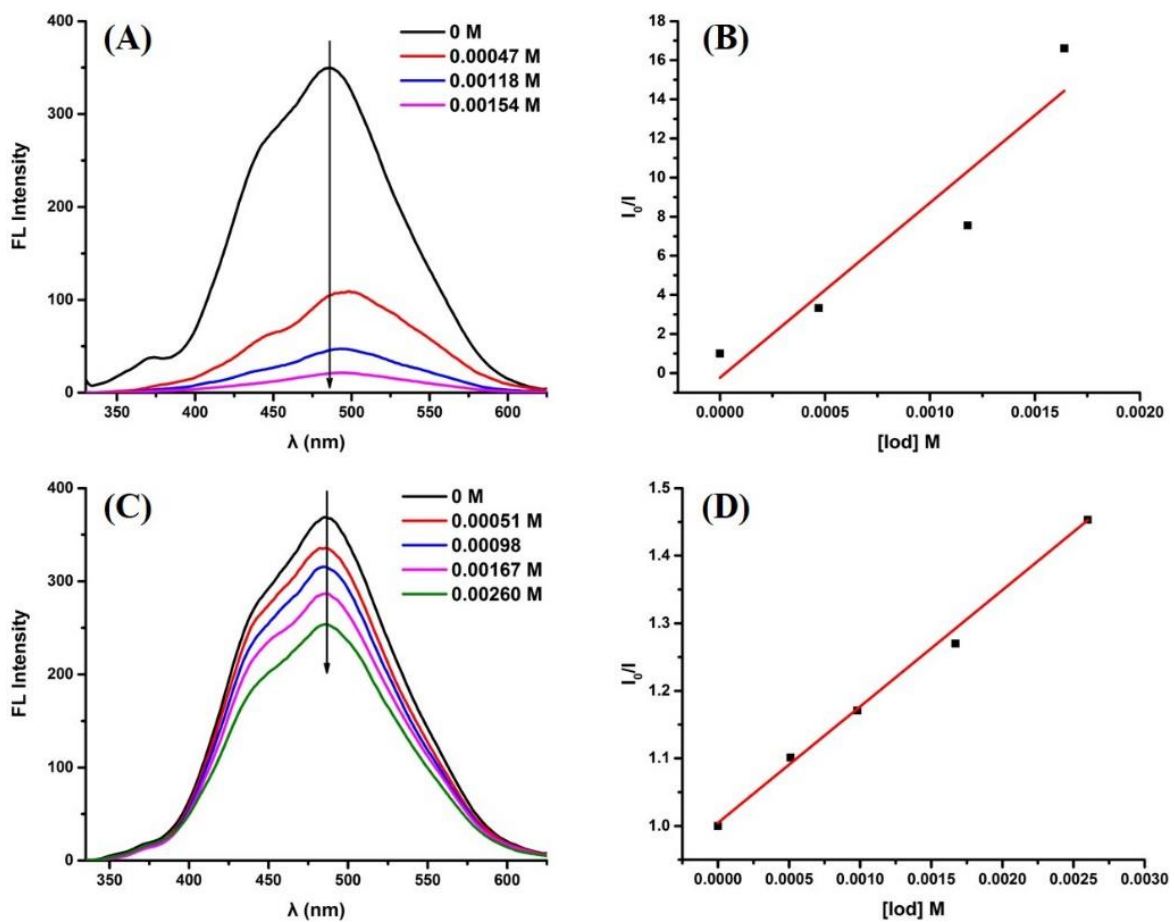

Figure S3. (A) Fluorescence quenching of BPC by EDB in acetonitrile, (B) SternVolmer treatment for BPC1/EDB fluorescence quenching, (C) Fluorescence quenching of BPC by Iod in acetonitrile, (D) Stern-Volmer treatment for BPC1/Iod fluorescence quenching. 

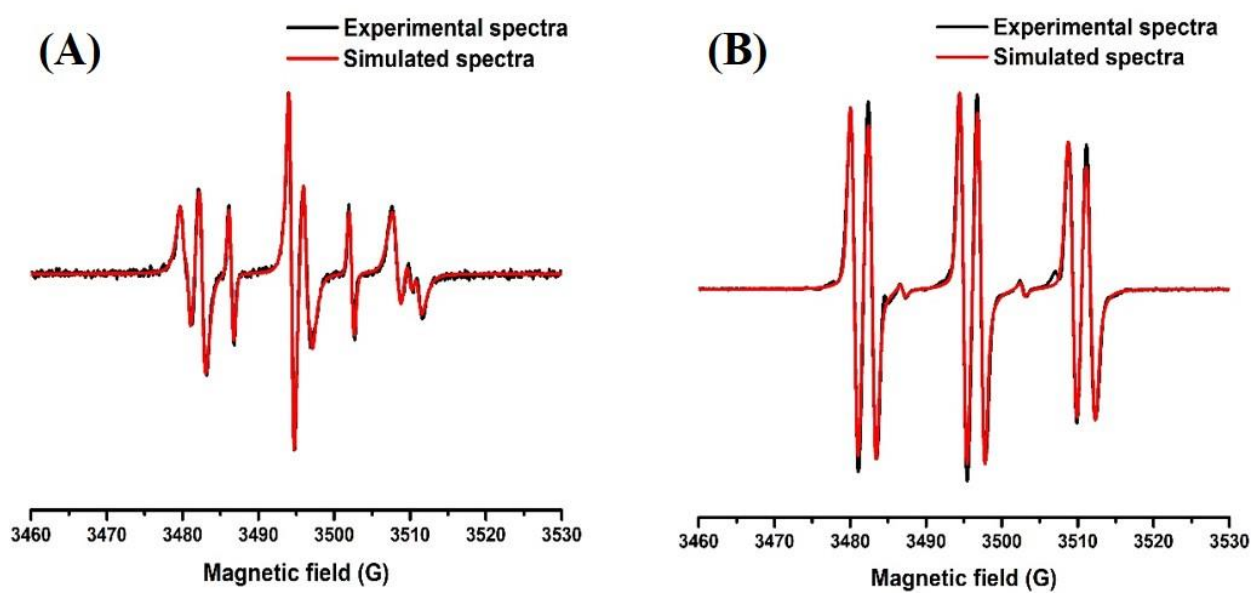

Figure S4. ESR-ST spectra of the radical adducts obtained in the presence of (A) BPC alone and (B) BPC/EDB/Iod upon LED@375 nm irradiation in tert-butylbenzene.

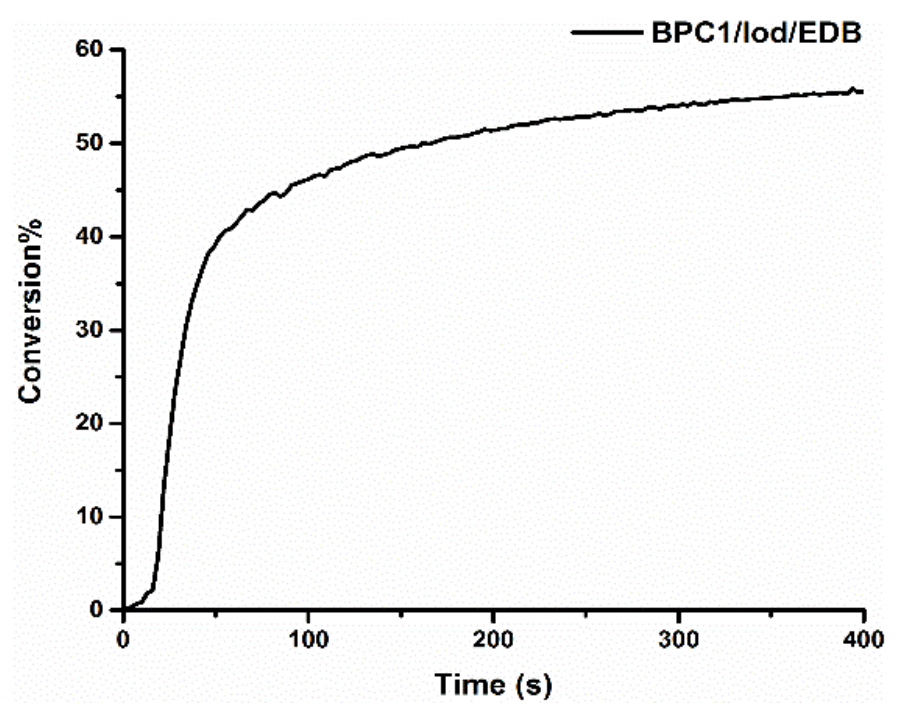

Figure S5. Photopolymerization profiles of TMPTA (acrylate function conversion vs irradiation time) in laminate upon LED@405 nm irradiation in the presence of $\mathrm{BPC} 1 / \mathrm{Iod} / \mathrm{EDB}(0.5 \% / 1 \% / 1 \%, \mathrm{w} / \mathrm{w} / \mathrm{w})$. The irradiation starts for $\mathrm{t}=10 \mathrm{~s}$.

\section{Synthesis of BPC:}

All reagents and solvents were purchased from Aldrich or Alfa Aesar and used as received without further purification. Mass spectroscopy was performed by the Spectropole of Aix-Marseille University. ESI mass spectral analyses were recorded with a 3200 QTRAP (Applied Biosystems SCIEX) mass spectrometer. The HRMS 
mass spectral analysis was performed with a QStar Elite (Applied Biosystems SCIEX) mass spectrometer. Elemental analyses were recorded with a Thermo Finnigan EA 1112 elemental analysis apparatus driven by the Eager 300 software. ${ }^{1} \mathrm{H}$ and ${ }^{13} \mathrm{C}$ NMR spectra were determined at room temperature in $5 \mathrm{~mm}$ o.d. tubes on a Bruker Avance 400 spectrometer of the Spectropole: ${ }^{1} \mathrm{H}(400 \mathrm{MHz})$ and ${ }^{13} \mathrm{C}(100 \mathrm{MHz})$. The ${ }^{1} \mathrm{H}$ chemical shifts were referenced to the solvent peaks $\mathrm{CDCl}_{3}(7.26 \mathrm{ppm})$ and the ${ }^{13} \mathrm{C}$ chemical shifts were referenced to the solvent peak $\mathrm{CDCl}_{3}$ (77.0 ppm). All photoinitiators were prepared with analytical purity up to accepted standards for new organic compounds ( $>98 \%)$ which was checked by high field NMR analysis.

\section{Synthesis of (9-ethyl-9H-carbazole-3,6-diyl)bis(phenylmethanone)}

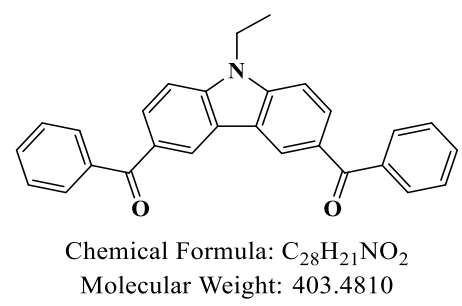

$\mathrm{AlCl}_{3}(7.20 \mathrm{~g}, 54 \mathrm{mmol}, \mathrm{M}=133.34 \mathrm{~g} / \mathrm{mol})$ was added by portion to a cooled solution of 9-ethyl-9H-carbazole $(5.27 \mathrm{~g}, 27 \mathrm{mmol}, \mathrm{M}=195.26 \mathrm{~g} / \mathrm{mol})$ and benzoyl chloride (7.6 g, $6.26 \mathrm{~mL}, 54 \mathrm{mmol}, \mathrm{M}=140.57 \mathrm{~g} / \mathrm{mol}, \mathrm{d}=1.211)$ dissolved in dry dichloromethane (DCM) (25 mL, stabilized with amylene). The solution was stirred at room temperature overnight. The solution was quenched with water. The organic phase was extracted several times with DCM. The organic phases were combined, dried over magnesium sulfate and the solvent removed under reduced pressure. The residue was suspended in a minimum of DCM and addition of pentane precipitated a white solid that was filtered off, washed several times with pentane and dried under vacuum (8.93 g, 82\% yield). ${ }^{1} \mathrm{H}$ NMR $\left(\mathrm{CDCl}_{3}\right) \delta: 1.53(\mathrm{t}, 3 \mathrm{H}, \mathrm{J}=7.2 \mathrm{~Hz}), 4.48(\mathrm{q}, 2 \mathrm{H}, \mathrm{J}=7.3 \mathrm{~Hz})$, 7.49-7.54 (m, 6H), 7.58-7.64 (m, 2H), 7.82-7.86 (m, 4H), 8.09 (dd, 2H, J = 8.6 Hz, J = $1.6 \mathrm{~Hz}), 8.59(\mathrm{~d}, 2 \mathrm{H}, \mathrm{J}=1.6 \mathrm{~Hz}) ;{ }^{13} \mathrm{C} \mathrm{NMR}\left(\mathrm{CDCl}_{3}\right) \delta: 139,38.2,108.7,122.8,124.2$, 128.3, 129.1, 129.7, 129.9, 131.9, 138.7, 143.2, 196.4; HRMS (ESI MS) m/z: theor: 403.1572 found: $403.1574[\mathrm{M}+\mathrm{H}]^{+}$detected). 